\title{
Cultural and Morphological Variability among the Isolates of Alternaria burnsii (Uppal, Patel and Kamat) Causing Blight of Cumin
}

\author{
S.B. Sawant and R.G. Parmar* \\ Department of Plant Pathology, B. A. College of Agriculture, Anand Agricultural University, \\ Anand-388110, Gujarat, India \\ *Corresponding author
}

\section{A B S T R A C T}

Cultural and morphological variability studies on three different media viz., Potato Dextrose Agar, Richard's Synthetic Agar and Czapek's Dox Agar revealed considerable

\section{Keywords}

Alternaria burnsii,

Cumin blight,

Cumin, Variability, Isolate

Article Info

Accepted:

04 July 2019

Available Online:

10 August 2019 variation among the isolates of $A$. burnsii indicated the existence of variability in the pathogen. Moreover, Potato Dextrose Agar and Czapek's Dox Agar were found as an excellent media to support the growth and spore formation of isolates of A. burnsii, respectively. Initially, the fungal growth was light green, sometimes whitish green septate mycelial growth and finally grey to black in color with dirty white to brownish colony margin and fluffy radial, plain irregular radial and fluffy knotting growth pattern on three different media. Among fifteen isolates of A. burnsii, distinct differences in terms of conidial length, breadth, beak length and number of septa were recorded. The average conidial length varied from 50.89 to $63.76 \mu \mathrm{m}$ and breadth ranges from 20.24 to $25.47 \mu \mathrm{m}$ with beak length of 28.73 to $47.33 \mu \mathrm{m}$. The transverse septa varied from 1 to 6 and longitudinal septa varied from to 0 to 3 , respectively. In the present studies, glaring differences in conidial size were noticed among the isolates even when same medium was used for the growth of the isolates. It can be assumed that variation in the isolates may be inherent since isolates were collected from diverse agroclimatic zones of Gujarat. Hence, these variations in the conidial size indicated the existence of variability in this pathogen

\section{Introduction}

Cumin (Cuminum cyminum L.) popularly known as Jeera or Jiroo is the most important spice crop inIndia. Gujarat is second largest producer next to Rajasthan with $50-55 \%$ of total production of India. Cumin crop suffers with blight disease caused by Alternaria burnsii. Cumin seed is used as culinary for flavouring vegetables, pickles, soups, etc. The seeds contain 17.7 per cent protein, 23.8 per cent fat, 35.5 per cent carbohydrates and 7.7 per cent minerals (Chadha, 2006). Cumin suffers from important diseases, viz., blight (Alternaria burnsii), wilt (Fusarium oxysporum f.sp. cumini) and powdery mildew (Erysiphe polygoni) which causes considerable qualitative and quantitative yield losses in the crop. Blight (A. burnsii) is of common occurrence in the areas where cumin is grown. Cumin blight was recorded for the first time from Kaira district of Gujarat. The 
causative agent was reported to be Alternaria burnsii by Uppal et al., (1938). Later on, it was reported from Rajasthan by Joshi (1955). The disease usually appears at flowering stage. The infected plants show small, isolated, whitish necrotic areas on the aerial parts, especially on tips of young leaves (Sharma, 2010). Diseased seed are small, deshaped, shriveled, very light and turn black in colour (Gemawat and Prasad, 1972). Various species of Alternaria have been reported to show variability in terms of cultural, morphological and molecular characteristics (Pandey et al., 2005; Raja et al., 2007; Singh and Singh, 2007; Varma et al., 2007; Pipaliya and Jadeja, 2008 and Kumar et al., 2008). Variability studies are important to document the changes occurring in populations and individual as variability in morphological, cultural and molecular traits indicate the existence of different pathotypes. The variability is well known phenomenon in genus Alternaria and may be noticed as changes in spore shape and size, growth and sporulation, pathogenicity, etc. understanding pathogen population structure and mechanisms by which variation arises within a population is of paramount importance for developing a successful disease management strategy lead to the development of resistant genotypes to the given set of pathogenic races. An attemptwas made to study the cultural and morphological variability among the isolates of Alternaria burnsii (Uppal, Patel and Kamat) causing blight of cumin

\section{Materials and Methods}

Cultural variability among the isolates of $A$. burnsii

The blight infected samples were collected from major cumin growing areas of Gujarat and isolations were made to study the cultural and morphological variation among the different isolates (Table 1).

\section{Growth characters on solid media}

For cultural variability the isolates of the pathogen were studied on three different media viz., Potato Dextrose Agar, Richard's Synthetic Agar and Czapek's Dox Agar medium sterilized in autoclave for 20 minutes at $15 \mathrm{lbs}$ p.s.i. The $5 \mathrm{~mm}$ disc of pure culture of isolates was inoculated at the center of the pre poured Petri plates from ten days old actively growing culture. All inoculated plates were incubated at $28 \pm 1{ }^{\circ} \mathrm{C}$ temperature in BOD incubator. Three repetitions were taken for each isolate. The growth rate was measured and colony characters, growth habit and sporulation visually observed after $24 \mathrm{hrs}$ of incubation till the complete growth of the pathogen in Petri plates.

\section{Morphological variability}

The morphological characters of different isolates of $A$. burnsii including size of conidia (length and breadth), beak length and number of septa (Transverse and longitudinal) were measured from 8 days old culture under high power magnification (45X). The photomicrograph were taken by using camera attachment binocular microscope to show the typical spore morphology of the isolates. The conidial measurement of different isolates were done by using SImage 2013 Beta software.

\section{Results and Discussion}

The findings of the present study as well as relevant discussion have been presented under the following heads.

\section{Cultural variability among the isolates of $A$. burnsii}

The study on cultural characteristics of isolates of $A$. burnsii was carried out on three different solid media viz., Potato Dextrose 
Agar, Richard's Synthetic Agar, Czapek's Dox Agar as described in 'materials and methods'. These isolates showed significant differences in cultural characters viz., colony color, colony margin, colony diameter and sporulation of the isolates of $A$. burnsii on three different solid media.

Growth characteristics of isolates of $A$. burnsii on different solid media

The result presented in Table 2 and depicted in Plate (1A-1C \& 2A-2C) revealed that there was a considerable variations among the colony characteristics of the different isolates on three different solid media.

\section{Colony diameter and sporulation of isolates of $A$. burnsii on different media}

\section{Colony diameter}

The result presented in Table 3 and Plate (1A1C) revealed significant differences between isolates and media and also interaction. Among the three different media tested, maximum colony diameter on fifth day of observation was recorded in Czapek's Dox Agar $(36.28 \mathrm{~mm})$.

The next media was Richard's Synthetic Agar $(33.51 \mathrm{~mm})$ followed by Potato Dextrose Agar (30.88 mm).

In case of different isolates, maximum colony diameter (40.77 $\mathrm{mm})$ was recorded in Ahmedabad isolate (Ab-13) and Banaskantha isolate (Ab-5). The next was the Morbi isolate (Ab-7) and Surendranagar isolate (Ab-15) with colony diameter (35.66) which was at par with Ahmedabad isolate (Ab-8) (35.44 mm), Patan isolate (Ab-6) and Surendranagar isolate (Ab-14) with (35.22 mm), Ahmedabad isolate (Ab-10) and Banaskantha isolate (Ab-2) with (34.11mm), Patan isolate (Ab-1) and Banaskantha isolate (Ab-9) with $(33.88 \mathrm{~mm})$.
The moderate growth was recorded in Morbi isolate $(\mathrm{Ab}-4)$ and Surendranagr isolate $(\mathrm{Ab}-$ 12) with $(28.55 \mathrm{~mm})$ and least growth was observed in Patan isolate (Ab-3) and Morbi isolate $(\mathrm{Ab}-11)$ with $(25.77 \mathrm{~mm})$.

The interaction between media and isolates was found significant, which indicated the variation among the isolates in utilizing the media. Among them, maximum colony diameter (49.33 $\mathrm{mm})$ was recorded in Banaskantha isolate (Ab-5) and Ahmedabad isolate (Ab-13) on Czapek's Dox Agar media which was at par with same isolates on Richard's Agar media (48.66 mm). The least colony diameter of $(18.66 \mathrm{~mm})$ was recorded in Patan isolate (Ab-3) and Morbi isolate (Ab11) on Richard's Synthetic Agar media.

Overall, the excellent colony growth was recorded on Czapek's Dox Agar media. The moderate growth was recorded on Richard's Synthetic Agar media and least growth was recorded in Potato Dextrose Agar media.

\section{Eighth day observation}

The result presented in Table 4 and Plate (2A2C) revealed significant differences between isolates and media and also interaction. Among the three different media tested, maximum colony diameter on eighth days of observation was recorded in Potato Dextrose Agar $(70.73 \mathrm{~mm})$. The next best media was Czapek's Dox Agar $(67.08 \mathrm{~mm})$ followed by Richard's Synthetic Agar (59.93mm).

In case of different isolates, maximum colony diameter (72.44 $\mathrm{mm})$ was recorded in Ahmedabad isolate (AB-8) which was at par with Patan isolate (Ab-1) and Banaskantha isolate (Ab-9) with (72.00 mm), Morbi isolate (Ab-7) and Surendranagar isolate (Ab-15) with $(69.11 \mathrm{~mm})$. The moderate growth was recorded in Patan isolate (Ab-6) and with (65.66 mm) which was at par with 
Banaskantha isolates (Ab-2, Ab-5) with (65.44 $\mathrm{mm}, 65.66 \mathrm{~mm})$ respectively, Ahmedabad isolates (Ab-10, Ab-13) with $(65.44 \mathrm{~mm}$, 65.66) respectively, Surendranagar isolates (Ab-12, Ab-14) with $(65.22 \mathrm{~mm}, 66.11 \mathrm{~mm})$ respectively and Morbi isolate (Ab-4) with $(65.22 \mathrm{~mm})$. The least growth was observed in Patan isolate (Ab-3) and Morbi isolate (Ab11) with $(54.55 \mathrm{~mm})$.

The interaction between media and isolates was found significant, which indicated the variation among the isolates in utilizing the media. Among them, maximum colony diameter $(78.66 \mathrm{~mm})$ was recorded in Morbi isolate (Ab-4), Surendranagar isolate (Ab-12) on Potato Dextrose agar media and Morbi isolate (Ab-7), Banaskantha isolate (Ab-9) on Czapek's Dox agar media The least colony diameter of $(46.33 \mathrm{~mm})$ was recorded in Patan isolate (Ab-3) and Morbi isolate (Ab-11) on Richard's Synthetic Agar media.

Overall, the excellent colony growth was recorded on Potato Dextrose Agar media. The moderate growth was recorded on Czapek's Dox Agar media and least growth was recorded in Richard's Synthetic Agar media.

\section{Sporulation}

With regard to sporulation, the result presented in Table 5 revealed that abundant sporulation was recorded in Potato Dextrose Agar media (8.62) which was at par with Czapek's Dox Agar media $(8.36 \mathrm{~mm})$. The sporulation was recorded scanty in Richard's Synthetic Agar media (8.09 mm).

In case of isolates, good sporulation (9.48) was recorded in Banaskantha isolate (Ab-2) and surendranagar isolate (Ab-12) which was at par with Banaskantha isolate (Ab-9), Patan isolate (Ab-6), Morbi isolate (Ab-7) and Surendranagar isolates (Ab-15) with (9.44, 9.34, 9.19, 8.86) respectively. Banaskantha isolate (Ab-5) with (8.63) which was at par with Ahmedabad isolates (Ab-3, Ab-8, Ab-10) with $(7.95,8.23,8.13)$ respectively. The moderate sporulation was recorded in Ahmedabad isolate (Ab-13) with (7.73) which was at par with Patan isolate (Ab-1) with (7.68), Surendranagar isolate (Ab-14) with (7.37) and Morbi isolate (Ab-11) with (7.35). The scanty sporulation was recorded in Morbi isolate $(\mathrm{Ab}-4)$ (6.48).

The interaction between media and isolates was found significant which indicated the variation among the isolates in utilizing the media. Among them, maximum sporulation (11.15) was recorded in Banaskantha isolate (Ab-2) and Surendranagar isolate (Ab-12) on Potato Dextrose Agar media which was at par with Patan isolate (Ab-6) with (10.34), Banaskantha isolate (Ab-9) with (10.33) and Ahmedabad isolate (Ab-10) with (10.14) on the same media. The least sporulation (5.04) was recorded in Morbi isolate (Ab-4) on Potato Dextrose Agar media.

Overall, the excellent sporulation was recorded on Potato dextrose agar media. Which was at par with Czapek's Dox Agar media and least growth was recorded in Richard's Synthetic Agar media.

\section{Morphological variability among the isolates of $A$. burnsii}

In all the isolates, the conidia were single, lateral, straight or curved, smooth walled with 1 to 6 septa, pale brown. However, the size of conidia varied among the isolates, some of them were very long and narrow, while some were fairly board. The result presented in Table 6-9 and Plate (1A-1C \& 2A-2C) revealed that there were distinct variations among the morphological characters viz., length and breadth of conidia, conidial beak length and conidial septation of the isolates of A. burnsii on seven different solid media. 
Table.1 List of Alternaria burnsii isolates collected from different locations

\begin{tabular}{|c|c|c|}
\hline Sr. No. & Isolate designation & Location of isolate \\
\hline $\mathbf{1}$ & $\mathrm{Ab}-1$ & Patan \\
\hline $\mathbf{2}$ & $\mathrm{Ab}-2$ & Banaskantha \\
\hline $\mathbf{3}$ & $\mathrm{Ab}-3$ & Patan \\
\hline $\mathbf{4}$ & $\mathrm{Ab}-4$ & Morbi \\
\hline $\mathbf{5}$ & $\mathrm{Ab}-5$ & Banaskantha \\
\hline $\mathbf{6}$ & $\mathrm{Ab}-6$ & Patan \\
\hline $\mathbf{7}$ & $\mathrm{Ab}-7$ & Morbi \\
\hline $\mathbf{8}$ & $\mathrm{Ab}-8$ & Ahmedabad \\
\hline $\mathbf{9}$ & $\mathrm{Ab}-9$ & Banaskantha \\
\hline $\mathbf{1 0}$ & $\mathrm{Ab}-10$ & Ahmedabad \\
\hline $\mathbf{1 1}$ & $\mathrm{Ab}-11$ & Morbi \\
\hline $\mathbf{1 2}$ & $\mathrm{Ab}-12$ & Surendranagar \\
\hline $\mathbf{1 3}$ & $\mathrm{Ab}-13$ & Ahmedabad \\
\hline $\mathbf{1 4}$ & $\mathrm{Ab}-14$ & Surendranagar \\
\hline $\mathbf{1 5}$ & $\mathrm{Ab}-15$ & Surendranagar \\
\hline
\end{tabular}

$\mathrm{Ab}$ - Alternaria burnsii

Table.2 Colony characteristics (colony color, colony margin and growth pattern) of isolates of $A$. burnsii on different media

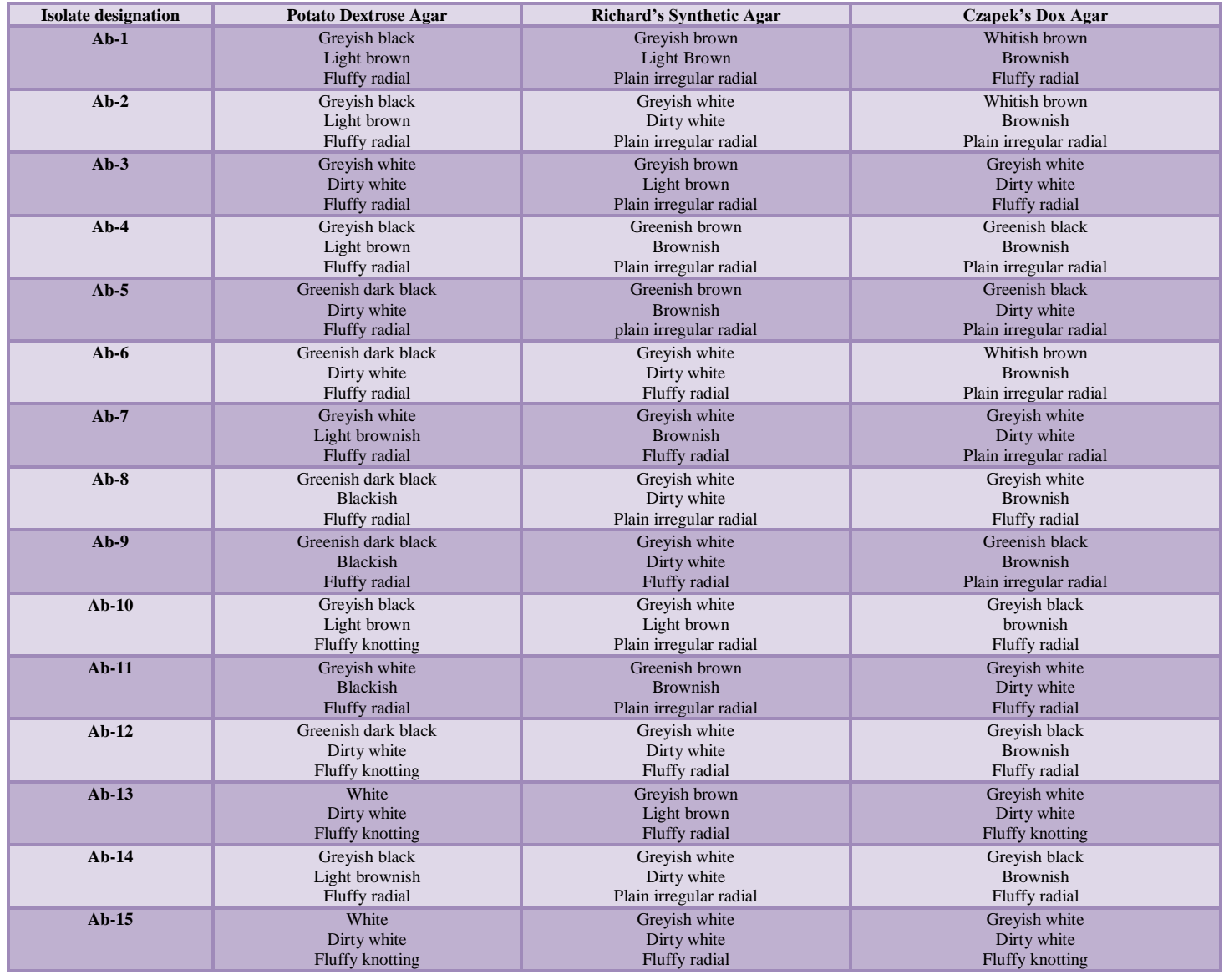


Table.3 Colony diameter of isolates of A. burnsii on different media on $5^{\text {th }}$ day

\begin{tabular}{|c|c|c|c|c|c|}
\hline \multirow{2}{*}{$\begin{array}{c}\text { Isolates/ } \\
\text { Media }\end{array}$} & \multicolumn{4}{|c|}{ Colony diameter (mm) } & \multirow[t]{2}{*}{ Mean $(\mathbf{m m})$} \\
\hline & Potato Dextrose Agar & Richard's Synthetic Agar & \multicolumn{2}{|c|}{ Czapek's Dox Agar } & \\
\hline Ab-1 & 34.66 & 33.00 & \multicolumn{2}{|c|}{34.00} & 33.88 \\
\hline Ab-2 & 31.66 & 38.00 & \multicolumn{2}{|c|}{32.66} & 34.11 \\
\hline Ab-3 & 33.00 & 18.66 & \multicolumn{2}{|c|}{25.66} & 25.77 \\
\hline Ab-4 & 24.66 & 22.33 & \multicolumn{2}{|c|}{38.66} & 28.55 \\
\hline Ab-5 & 24.33 & 48.66 & \multicolumn{2}{|c|}{49.33} & 40.77 \\
\hline Ab-6 & 35.66 & 38.33 & \multicolumn{2}{|c|}{31.66} & 35.22 \\
\hline Ab-7 & 31.66 & 33.00 & \multicolumn{2}{|c|}{42.33} & 35.66 \\
\hline Ab-8 & 32.00 & 38.67 & \multicolumn{2}{|c|}{35.66} & 35.44 \\
\hline Ab-9 & 34.66 & 33.00 & \multicolumn{2}{|c|}{34.00} & 33.88 \\
\hline Ab-10 & 31.66 & 38.00 & \multicolumn{2}{|c|}{32.66} & 34.11 \\
\hline Ab-11 & 33.00 & 18.66 & \multicolumn{2}{|c|}{25.66} & 25.77 \\
\hline Ab-12 & 24.66 & 22.33 & \multicolumn{2}{|c|}{38.66} & 28.55 \\
\hline Ab-13 & 24.33 & 48.66 & \multicolumn{2}{|c|}{49.33} & 40.77 \\
\hline Ab-14 & 35.66 & 38.33 & \multicolumn{2}{|c|}{31.66} & 35.22 \\
\hline Ab-15 & 31.66 & \multirow{2}{*}{$\begin{array}{l}33.00 \\
3351\end{array}$} & \multicolumn{2}{|c|}{42.33} & 35.66 \\
\hline Mean & 30.88 & & & & \\
\hline & & S.Em. \pm & C.D. at $5 \%$ & C. & \\
\hline & Media & 0.309 & 0.870 & & \\
\hline & Isolates & 0.691 & 1.944 & & \\
\hline & Isolates x Media & 1.197 & 3.368 & & \\
\hline
\end{tabular}

Table.4 Colony diameter of isolates of $A$. burnsii on different media on $8^{\text {th }}$ day

\begin{tabular}{|c|c|c|c|c|c|c|}
\hline \multirow{2}{*}{$\begin{array}{c}\text { Isolates/ } \\
\text { Media }\end{array}$} & \multicolumn{5}{|c|}{ Colony diameter (mm) } & \multirow{2}{*}{$\begin{array}{l}\text { Mean } \\
(\mathbf{m m})\end{array}$} \\
\hline & Potato Dextrose Agar & \multicolumn{2}{|c|}{ Richard's Synthetic Agar } & \multicolumn{2}{|c|}{ Czapek's Dox Agar } & \\
\hline Ab-1 & 73.00 & \multicolumn{2}{|c|}{64.33} & & 78.66 & 72.00 \\
\hline Ab-2 & 73.00 & \multicolumn{2}{|c|}{64.00} & & 59.33 & 65.44 \\
\hline Ab-3 & 64.00 & \multicolumn{2}{|c|}{46.33} & & 53.33 & 54.55 \\
\hline Ab-4 & 78.66 & \multicolumn{2}{|c|}{48.33} & & 68.66 & 65.22 \\
\hline Ab-5 & 74.00 & \multicolumn{2}{|c|}{59.33} & & 63.66 & 65.66 \\
\hline Ab-6 & 70.33 & \multicolumn{2}{|c|}{59.66} & & 68.66 & 66.22 \\
\hline Ab-7 & 58.33 & \multicolumn{2}{|c|}{70.33} & & 78.66 & 69.11 \\
\hline Ab-8 & 78.33 & \multicolumn{2}{|c|}{74.33} & & 64.66 & 72.44 \\
\hline Ab-9 & 73.00 & \multicolumn{2}{|c|}{64.33} & & 78.66 & 72.00 \\
\hline Ab-10 & 73.00 & \multicolumn{2}{|c|}{64.00} & & 59.33 & 65.44 \\
\hline Ab-11 & 64.00 & \multicolumn{2}{|c|}{46.33} & & 53.33 & 54.55 \\
\hline Ab-12 & 78.66 & \multicolumn{2}{|c|}{48.33} & & 68.66 & 65.22 \\
\hline Ab-13 & 74.00 & \multicolumn{2}{|c|}{59.33} & & 63.66 & 65.66 \\
\hline Ab-14 & 70.33 & \multicolumn{2}{|c|}{59.66} & & 68.33 & 66.11 \\
\hline Ab-15 & 58.33 & & & & 78.66 & 69.11 \\
\hline Mean & 70.73 & & & & 67.08 & 72.00 \\
\hline & & S.Em. \pm & C.D. at & $\%$ & C.V. & \\
\hline & Iedia & 0.608 & 1.71 & & 6.1 & \\
\hline & olates & 1.360 & 3.82 & & & \\
\hline Isola & s x Media & 2.355 & 6.62 & & & \\
\hline
\end{tabular}


Table.5 Relative amount of sporulation of isolates of $A$. burnsii on different media

\begin{tabular}{|c|c|c|c|c|c|c|}
\hline \multirow{2}{*}{$\begin{array}{c}\text { Isolates/ } \\
\text { Media }\end{array}$} & \multicolumn{5}{|c|}{ Sporulation on media(n $\left.\times 10^{4}\right)$} & \multirow[t]{2}{*}{ Mear } \\
\hline & Potato Dextrose Agar & \multicolumn{2}{|c|}{ Richard's Synthetic Agar } & \multicolumn{2}{|c|}{ Czapek's Dox Agar } & \\
\hline Ab-1 & 7.24 & \multicolumn{2}{|c|}{7.90} & \multicolumn{2}{|r|}{7.90} & 7.68 \\
\hline Ab-2 & 11.15 & \multicolumn{2}{|c|}{8.15} & & 9.15 & 9.48 \\
\hline Ab-3 & 7.18 & \multicolumn{2}{|c|}{7.84} & & 8.84 & 7.95 \\
\hline Ab-4 & 5.04 & \multicolumn{2}{|c|}{7.70} & & 6.70 & 6.48 \\
\hline Ab-5 & 8.75 & \multicolumn{2}{|c|}{9.08} & & 8.08 & 8.63 \\
\hline Ab-6 & 10.34 & \multicolumn{2}{|c|}{8.34} & & 9.34 & 9.34 \\
\hline Ab-7 & 9.64 & \multicolumn{2}{|c|}{8.64} & & 9.30 & 9.19 \\
\hline Ab-8 & 8.25 & \multicolumn{2}{|c|}{8.25} & & 7.91 & 8.13 \\
\hline Ab-9 & 10.33 & \multicolumn{2}{|c|}{8.66} & & 9.33 & 9.44 \\
\hline Ab-10 & 10.14 & \multicolumn{2}{|c|}{5.42} & & 9.14 & 8.23 \\
\hline Ab-11 & 7.24 & \multicolumn{2}{|c|}{7.90} & & 6.90 & 7.35 \\
\hline Ab-12 & 11.15 & \multicolumn{2}{|c|}{8.15} & & 9.15 & 9.48 \\
\hline Ab-13 & 7.18 & \multicolumn{2}{|c|}{8.51} & & 7.51 & 7.73 \\
\hline Ab-14 & 7.04 & \multicolumn{2}{|c|}{7.70} & & 7.37 & 7.37 \\
\hline Ab-15 & 8.75 & & & & 8.75 & 8.86 \\
\hline Mean & 8.62 & & & & 8.36 & \\
\hline & & S.Em.土 & C.D. at & & C.V & \\
\hline & Media & 0.122 & 0.34 & & 9. & \\
\hline & Isolates & 0.273 & 0.76 & & & \\
\hline Iso & tes $x$ Media & 0.472 & 1.32 & & & \\
\hline
\end{tabular}

Table.6 Conidial length of isolates of $A$. burnsii on different media

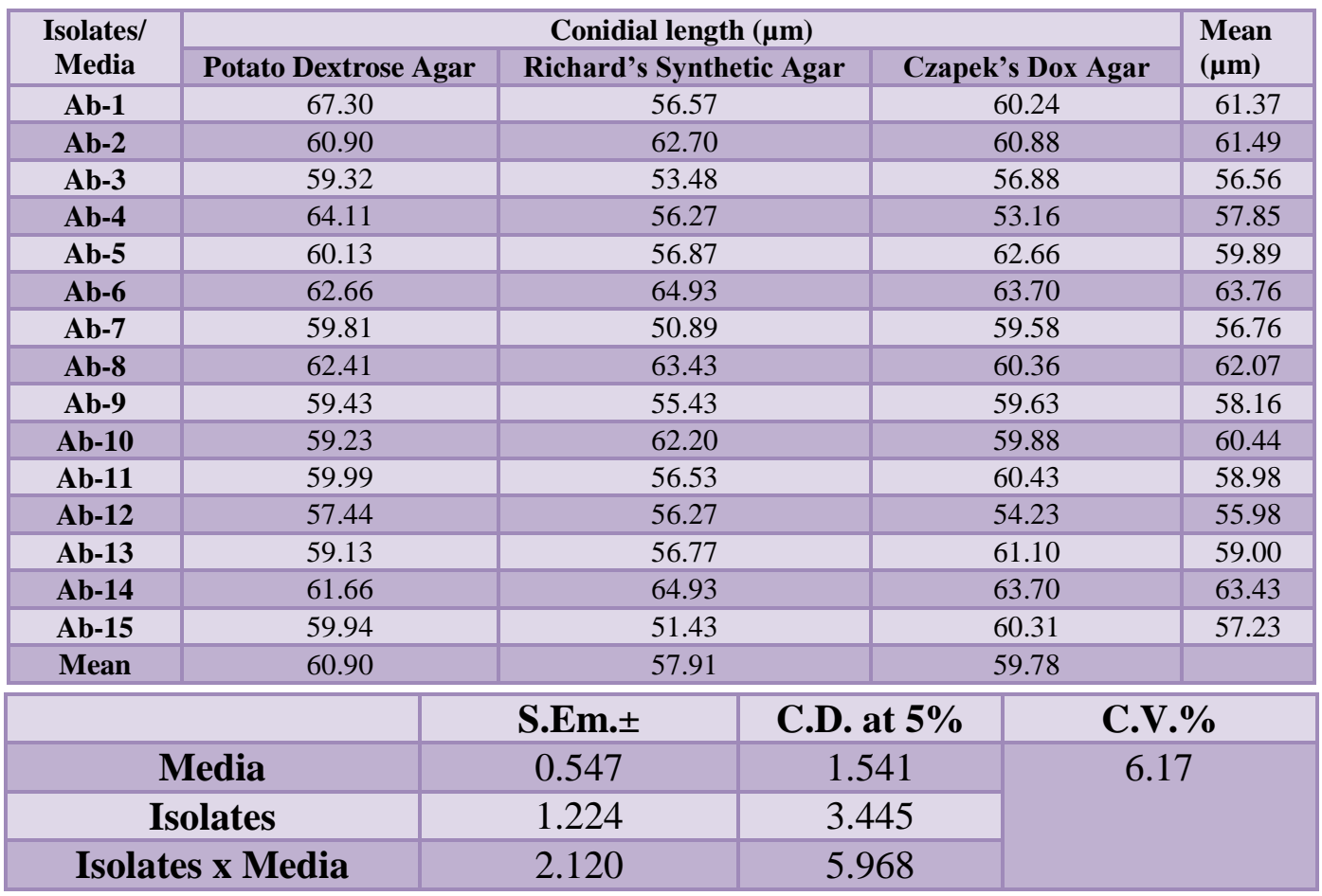


Table.7 Conidial breadth of isolates of $A$. burnsii on different media

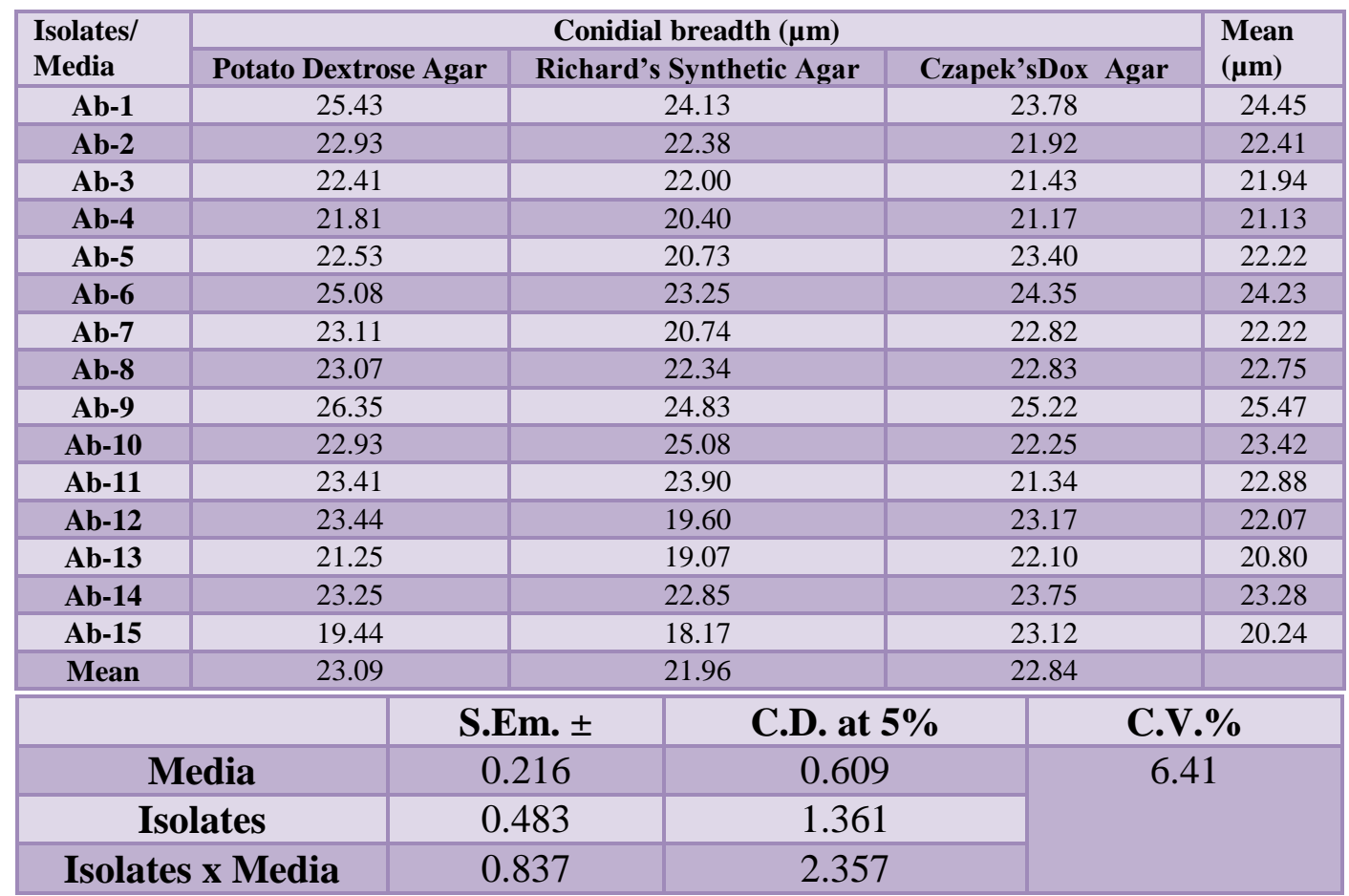

Table.8 Beak length of conidia of isolates of A. burnsii on different media

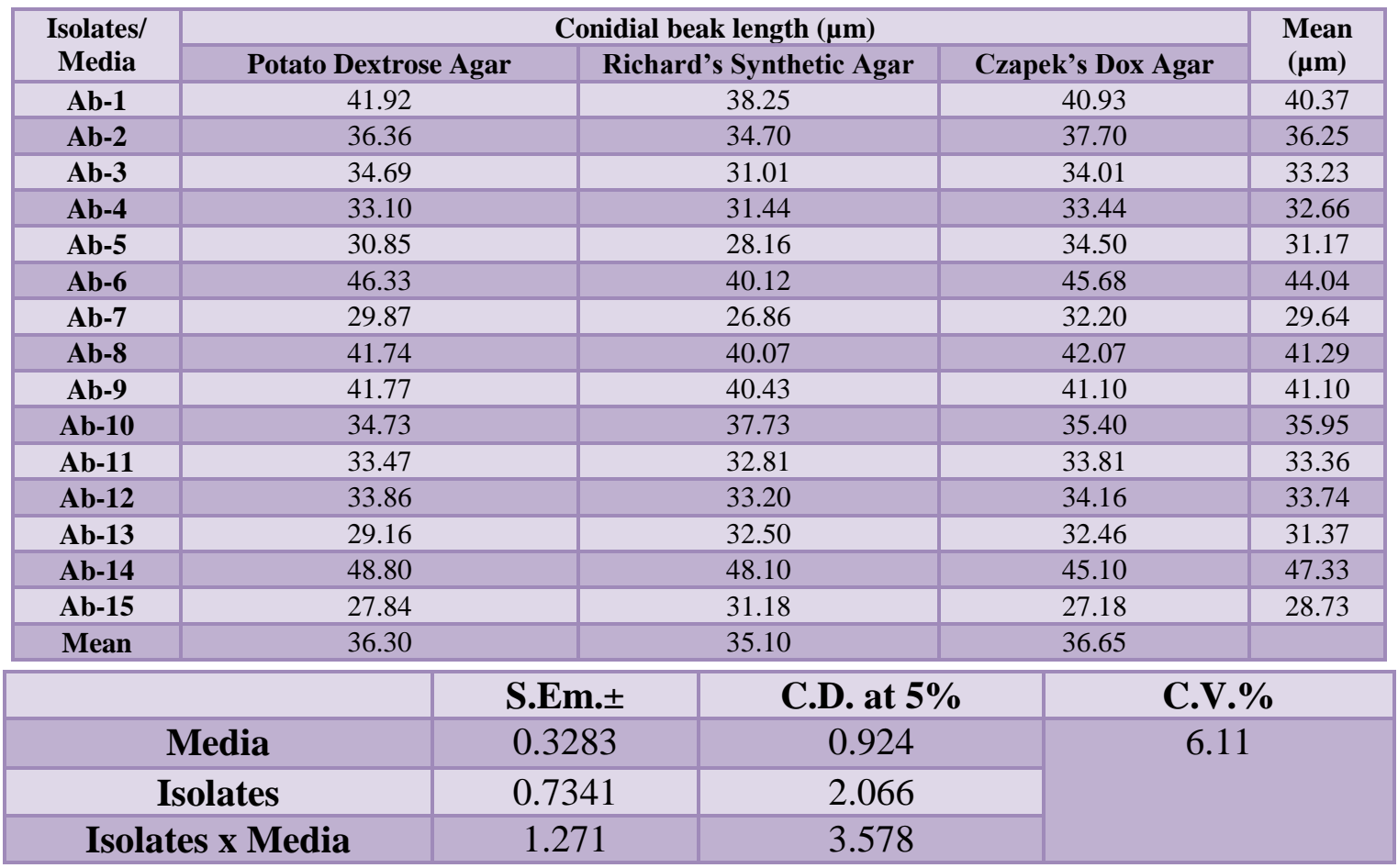


Table.9 Conidial septation of isolates of A. burnsii on different media

\begin{tabular}{|c|c|c|c|c|c|c|}
\hline \multirow{3}{*}{$\begin{array}{l}\text { Isolates/ } \\
\text { Media }\end{array}$} & \multicolumn{6}{|c|}{ Conidial septation (No.) } \\
\hline & \multicolumn{2}{|c|}{$\begin{array}{c}\text { Potato Dextrose } \\
\text { Agar }\end{array}$} & \multicolumn{2}{|c|}{$\begin{array}{c}\text { Richard's Synthetic } \\
\text { Agar }\end{array}$} & \multicolumn{2}{|c|}{$\begin{array}{c}\text { Czapek's Dox } \\
\text { Agar }\end{array}$} \\
\hline & $\mathrm{T}^{*}$ & $\mathrm{~L}^{*}$ & $\mathrm{~T}$ & $\mathrm{~L}$ & $\mathrm{~T}$ & $\mathrm{~L}$ \\
\hline Ab-1 & $0-3$ & $0-1$ & $0-2$ & $0-1$ & $0-2$ & $0-1$ \\
\hline Ab-2 & $1-3$ & $0-2$ & $0-2$ & $0-2$ & $0-3$ & $0-2$ \\
\hline Ab-3 & $1-3$ & $0-1$ & $0-2$ & $0-1$ & $0-3$ & $0-2$ \\
\hline Ab-4 & $1-4$ & $0-1$ & $0-1$ & $0-1$ & $1-2$ & $0-1$ \\
\hline Ab-5 & $1-5$ & $0-2$ & $0-2$ & $0-1$ & $1-2$ & $0-1$ \\
\hline Ab-6 & $1-4$ & $0-2$ & $0-2$ & $0-1$ & $1-3$ & $0-1$ \\
\hline Ab-7 & $0-5$ & $0-2$ & $0-3$ & $0-2$ & $0-2$ & $0-2$ \\
\hline Ab-8 & $1-6$ & $0-3$ & $0-2$ & $0-2$ & $0-3$ & $0-2$ \\
\hline Ab-9 & $1-5$ & $0-2$ & $0-2$ & $0-1$ & $1-3$ & $0-1$ \\
\hline Ab-10 & $1-5$ & 0-1 & $0-2$ & $0-1$ & $1-3$ & $0-2$ \\
\hline Ab-11 & $1-3$ & $0-1$ & $0-2$ & $0-2$ & $1-4$ & $0-2$ \\
\hline Ab-12 & $1-4$ & $0-2$ & $0-3$ & $0-1$ & $1-2$ & $0-1$ \\
\hline Ab-13 & $1-5$ & $0-1$ & $0-2$ & $0-1$ & $1-3$ & $0-2$ \\
\hline Ab-14 & $1-3$ & $0-2$ & $0-2$ & $0-1$ & $0-4$ & $0-2$ \\
\hline Ab-15 & $1-3$ & $0-1$ & $0-2$ & $0-1$ & $1-3$ & $0-1$ \\
\hline
\end{tabular}

*T $=$ Transverse, $\mathrm{L}=$ Longitudinal

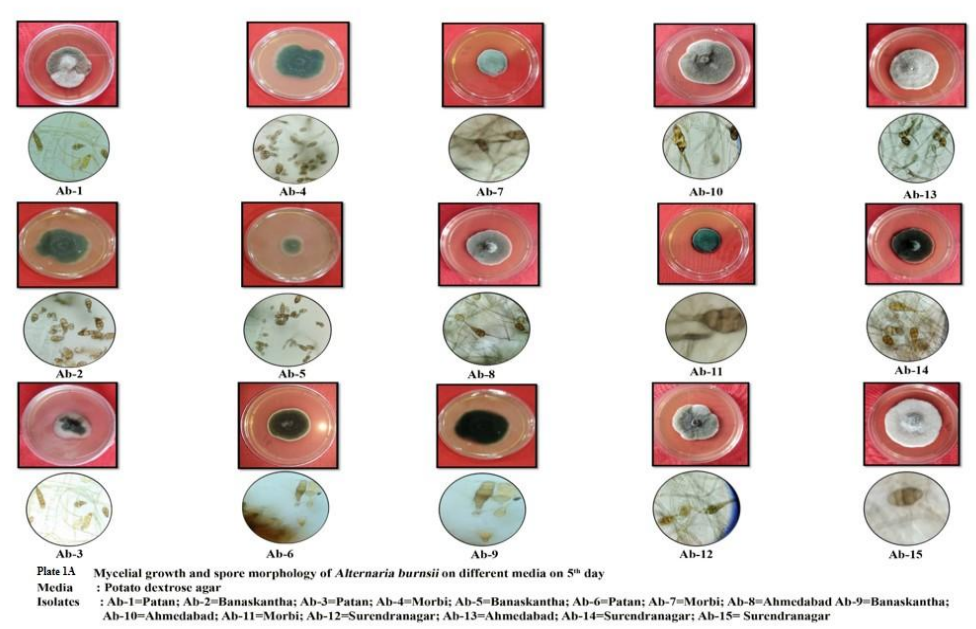



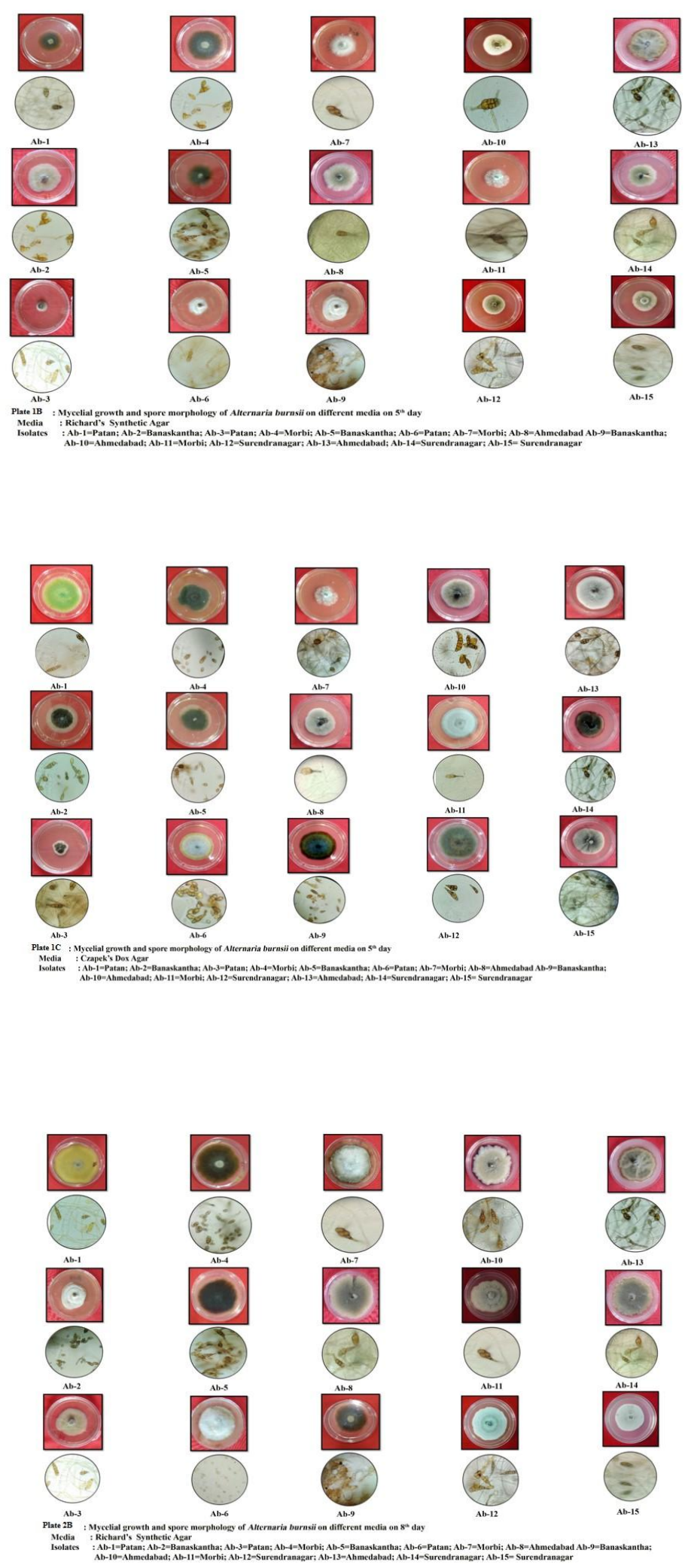

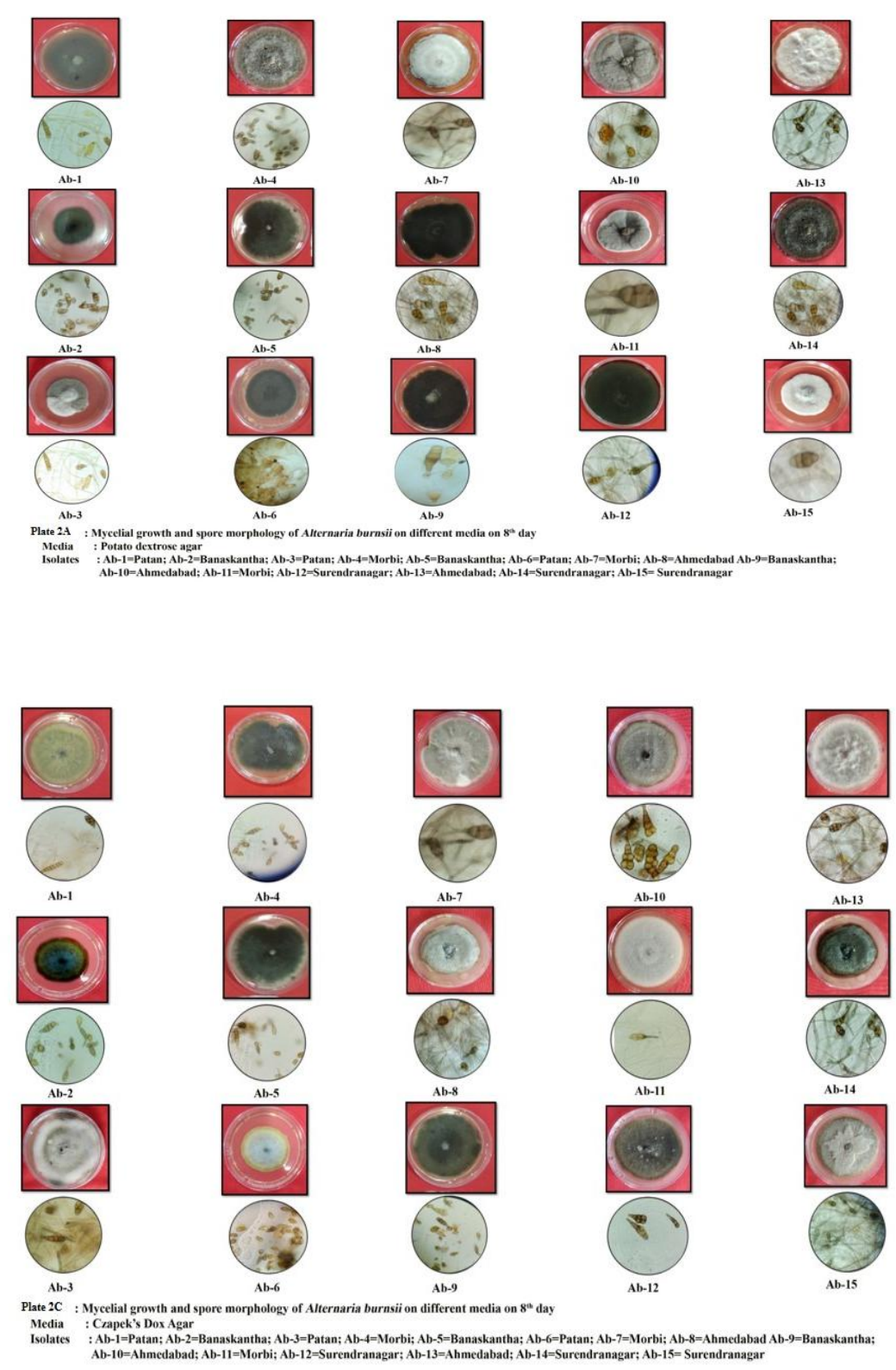

\section{Conidial length}

The result presented in Table 6 revealed significant differences between isolates and media and also interaction Among the three different media tested, maximum conidial length was recorded in Potato Dextrose Agar $(60.90 \mu \mathrm{m})$ which was at par with Czapek's Dox agar $(59.78 \mu \mathrm{m})$. While, the minimum conidial length was recorded in Richard's Synthetic Agar $(57.91 \mu \mathrm{m})$.
In case of different isolates, maximum (63.76 $\mu \mathrm{m})$ conidial length was noticed in Patan isolate (Ab-6) which was at par with Patan isolate (Ab1) with $(61.37 \mu \mathrm{m})$, Banaskantha isolate $(\mathrm{Ab}-2)$ with $(61.49 \mu \mathrm{m})$, Ahmedabad isolate (Ab-8, Ab-10) with $(62.07 \mu \mathrm{m}, 60.44 \mu \mathrm{m})$ respectively and Surendranagar isolate (Ab-14) with (63.43 $\mu \mathrm{m})$. The minimum conidial length was recorded in Surendranagar isolate (Ab-12) with $(55.98 \mu \mathrm{m})$. 
The interaction between media and isolates was found significant, which indicated the variation among the isolates in utilizing the media. Among them, maximum $(67.30 \mu \mathrm{m})$ conidial length was recorded in Patan isolate $(\mathrm{Ab}-1)$ in Potato Dextrose Agar media which was at par with Morbi isolate (Ab-4) with $(64.11 \mu \mathrm{m})$, Patan isolate $(\mathrm{Ab}-6)$ with $(62.66 \mu \mathrm{m})$, Ahmedabad isolate (Ab-8) with $(62.41 \mu \mathrm{m})$ amd Surendranagar isolate (Ab-14) with (61.66 $\mu \mathrm{m})$ same media. Banaskantha isolate (Ab-2) with $(62.70 \mu \mathrm{m})$, Patan isolate (Ab-6) with $(64.93 \mu \mathrm{m})$, Ahmedabad isolates (Ab-8, Ab-10) with $(63.43 \mu \mathrm{m}, 62.20 \mu \mathrm{m})$ respectively and Surendranagar isolate $(\mathrm{Ab}-14)$ with $(64.93 \mu \mathrm{m})$ on Richard's Synthetic Agar media. Banaskantha isolate (Ab-5) with $(62.66 \mu \mathrm{m})$, Patan isolate $(\mathrm{Ab}-6)$ with $(63.70 \mu \mathrm{m})$ and Surendranagar isolate $(\mathrm{Ab}-14)$ with $(60.31 \mu \mathrm{m})$ on Czapek's Dox Agar media. The minimum conidial length was noticed in Morbi isolate (Ab-7) $(50.89 \mu \mathrm{m})$ in Richard's Synthetic Agar media.

\section{Conidial breadth}

The result presented in Table 7 revealed significant differences between isolates and media and also interaction. Among the three different media tested, maximum conidial breadth $(23.09 \mu \mathrm{m})$ was noticed in Potato Dextrose Agar which was at par with Czapek's Dox Agar $(22.84 \mu \mathrm{m})$. While, the minimum conidial breadth $(21.96 \mu \mathrm{m})$ was noticed in Richard's Synthetic Agar media.

With respect to different isolates, maximum $(25.47 \mu \mathrm{m})$ conidial breadth was noticed in Banaskantha isolate (Ab-9) which was at par with Patan isolates (Ab-1, Ab-6) with (24.45 $\mu \mathrm{m}, 24.23 \mu \mathrm{m})$ respectively. Followed by Ahmedabad isolate (Ab-10) with $(23.42 \mu \mathrm{m})$ which was at par with Banaskantha isolates (Ab-2, Ab-5) with (22.41 $\mu \mathrm{m}, 22.22 \mu \mathrm{m})$ respectively, Morbi isolate (Ab-7, Ab-11) with (22.22 $\mu \mathrm{m}, \quad 22.88 \mu \mathrm{m}) \quad$ respectively, Surendranagar isolates (Ab-12, Ab-14) with $(22.07 \mu \mathrm{m}, 23.28 \mu \mathrm{m})$ respectively and Ahmedabad isolate (Ab-8) with $(22.75 \mu \mathrm{m})$.
The minimum conidial breadth was recorded in Surendranagar isolate (Ab-15) with $(20.24 \mu \mathrm{m})$.

The interaction between media and isolates was found significant. Among them, maximum conidial breadth was recorded in Banaskantha isolate $(\mathrm{Ab}-9)(26.35 \mu \mathrm{m})$ in Potato Dextrose Agar media which was at par with Patan isolates (Ab-1, Ab-6) with $(25.43 \mu \mathrm{m}, 25.08$ $\mu \mathrm{m})$ on same media. Ahmedabad isolate (Ab10) with $(25.08 \mu \mathrm{m})$, Patan isolate (Ab-1) with (24.13 $\mu \mathrm{m})$, Banaskantha isolate (Ab-9) with $(24.83 \mu \mathrm{m})$ on Richard's Synthetic Agar media. Patan isolate $(\mathrm{Ab}-6)$ with $(24.35 \mu \mathrm{m})$ and Banaskantha isolate (Ab-9) with $(25.22 \mu \mathrm{m})$ on Czapek's Dox Agar media. The minimum conidial breadth was recorded in Surendranagar isolate $(\mathrm{Ab}-15)(18.17 \mu \mathrm{m})$ in Richard's Synthetic Agar media.

\section{Conidial beak length}

The result presented in Table 8 revealed significant differences between isolates, media and their interaction. Among the three different media tested, longest conidial beak was recorded in Czapek'sDox Agar (36.65 $\mu \mathrm{m})$ which was at par with Potato Dextrose Agar $(36.30 \mu \mathrm{m})$. While, the smallest conidial beak length was recorded in Richard's Synthetic Agar $(35.10 \mu \mathrm{m})$.

In case of different isolates, longest $(47.33 \mu \mathrm{m})$ conidial beak length was recorded in Surendranagar isolate (Ab-14). The minimum conidial beak length was recorded in Surendranagar isolate (Ab-15) with $(28.73 \mu \mathrm{m})$.

The interaction between media and isolates was found significant. Among them, longest (48.80 $\mu \mathrm{m})$ conidial beak length was recorded in Surendranagar isolate (Ab-14) on Potato Dextrose Agar media which was at par with Patan isolate (Ab-6) with $(46.33 \mu \mathrm{m})$ on same media. Surendranagar isolate (Ab-14) with $(48.10 \mu \mathrm{m})$ on Richard's Synthetic Agar media and Patan isolate (Ab-6) (45.68 $\mu \mathrm{m})$ on Czapek's Dox Agar media. The smallest conidial beak length was recorded in Morbi 
isolate $(\mathrm{Ab}-7) \quad(26.86 \mu \mathrm{m})$ on Richard's Synthetic Agar media.

\section{Conidial septation}

The result presented in Table 9 revealed significant differences among the isolates with respect to transverse and longitudinal septation of conidia in different media. The maximum numbers of transverse septa were associated with the Ahmedabad isolate $(\mathrm{Ab}-8)$ in the range of 1 to 6 in Potato Dextrose Agar media and least septation was recorded in Morbi isolate $(\mathrm{Ab}-4)$ in the range of 0 to 1 in Richard's Synthetic Agar media. The number of longitudinal septa was higher in the Ahmedabad isolate (Ab-8) 0-3 on Potato Dextrose Agar media. Overall, the average number of septation among the isolates varied from 1to 6 transverse and 0 to 3 longitudinal septa (Table-9).

These observations are in conformity with the findings of earlier workers Singh et al., (2016); Mali et al., (2017); Pipaliya and Jadeja, 2008; Shekhawat et al., (2013); Paul et al., (2015) who reported differences among the isolates of A. burnsii in terms of conidial length, breadth and number of septation. Several workers Singh and Prasada (1973); Kaul and Saxena (1988); Singh et al., (2001); Gopinath (2002); Pandey et al., 2005; Rahmatzai et al., 2016; Kumar et al., (2003); Mehta et al., (2003); Jadhav et al., (2011); Bassadat et al., (2014) also observed diversity in cultural and morphological characters of different isolates of Alternaria spp.

Thus, the present findings tallied with the studies carried out by earlier workers. Morphological variation i.e. conidial size in the isolates of $A$. burnsii could be due to nutrition rather than a characteristic pathological variation. However, in the present studies glaring differences in conidial size were noticed among the isolates even when same medium was used for the growth of the isolates. It can be assumed that variation in the isolates may be inherent since isolates were collected from diverse agro climatic zones of Gujarat. Hence, these variations in the conidial size indicated the existence of variability in this pathogen.

\section{Acknowledgement}

The authors wish to express their appreciation to Anand Agricultural University, Anand, Gujarat, India for providing best facility to work.

\section{References}

Chadha, K. L., 2006. Handbook of Horticulture. 713-714.

Gemawat, P. D. and Prasad 1972. Efficacy of different fungicide for the control of Alternaria blight of cuminum cyminum. L. Indian Phytopathology. 22 (1): 49-52.

Gopinath, H., 2002. Physiological studies on Alternaria alternata pathogenic to Solanum khasianum. Journal of Mycopathology Research. 40 (2): 207209.

Jadhav, B. M., Perane, R. R., Kale, A. A. and Pawar, N. B. 2011. Morphological, pathological and molecular variability among Alternaria macrospora isolates causing leaf blight of cotton. Indian Phytopathology. 64 (3): 254-257.

Joshi, N. C., 1955. Note on two diseases of Cuminum cyminum L. hitherto unreported from Ajmer State. Science and Culture. 21: 101-102.

Kaul, A. K. and Saxena, H. K. 1988. Physiologic specialization in Alternaria solani causing early blight of potato, Cultural and Physiologic Variability. Journal of Mycology. 8 (2): 128-132.

Kumar, S., Sangwan, M. S., Mehta, N. and Kumar, R. 2003. Pathogenic diversity in isolates of Alternaria brassicae infecting rapeseed and mustard. Journal of Mycology. 33 (1): 59-64.

Kumar, V., Haldar, S., Pandey, K. K., Singh, R. P., Singh, A. K. and Singh, P. C. 2008. Cultural, morphological, pathogenic and molecular variability amongst tomato isolates of Alternaria solani in India.Journal of Biotechnology.24: 10031009. 
Mali, P. S., Jaiman, R. K. and Parmar, A. T. 2017. Variability of blight pathogen (Alternaria burnsii Uppal et al.,) of cumin (Cuminum cyminum). CABI. 35: 977-981.

Mehta, N., Sangwan, M. S. and Srivastava, M. P. 2003. Morphological and pathological variation in rapeseed and mustard isolates of Alternaria brassicae. Indian Phytopathology. 56 (2): 188-190.

Pandey, K. K., Pandey, P. K. and Rai, M. 2005. Molecular characterization, cultural and pathogenic variability of Alternaria solani isolates. Journal of plant Pathology.35 (3): 483

Paul, N. C., Deng, J. X., Lee, H. B. and Yu, S. H. 2015. Characterization \& Pathogenicity of Alternaria burnsii from seeds of Cucurbita maxima (cucurbitaceae) in Bangladesh. Mycobiology.43 (4): 384-391.

Pipaliya, B. H. and Jadeja, K. B. 2008. Cultural variability and mancozeb sensitivity of different isolates of $A$. burnsii $\mathrm{L}$. Indian Journal of Mycology and Plant Pathology. 38 (1): 121-122.

Rahmatzai, N., Madkour, M., Ahmady, A., Hazim, Z. and Mousa, A. 2016. Morphological, pathogenic, cultural and physiological variability of the isolates of Alternaria solani causing early blight of tomato. International Journal of Advance Research. 4 (11): 808-817.

Raja, P., Reddy, A., and Ramama, V. 2007. Morphological and biological variability of Alternaria sp. causing leaf spot and fruit rot of brinjal. Journal of Mycology and Plant Pathology. 37(2): 336-338.

Sharma, S., 2010. Studies on cumin blight incited by Alternaria burnsii (Uppal,
Patel and Kamat) and its management. M. Sc. thesis, Anand Agricultural University, Anand, India.

Shekhawat, N., Trivedi, A., Kumar, A. and Sharma, S. 2013. Management of Alternaria burnsii causing blight of cumin. International journal of plant protection. 6(2): 280-284.

Singh, A. K. and Singh, R. P. 2007. Morphological and pathological variations in wheat isolates of Alternaria triticina. Journal of Mycology and Plant Pathology. 37 (1): 159.

Singh, S. D., and Prasada, R. 1973. Studies on physiology and control of Alternaria cyamopsidis the incitant of blight disease of guar. Journal Mycology and Plant Pathology. 3: 33-39.

Singh, S., Bairwa, S., Triwedi, A., Meena, R., Meena, S. and Prasad, D. 2016. Morphological \& molecular variability in Alternaria burnsii \& Alternaria alternate causing blight disease of cumin (Cuminum cyminum). International Journal of Bio- Resource \& Stress Management.7: 1336-1345.

Singh, V., Kumar, P. and Sinha, A. P. 2001. Influence of different media, $\mathrm{pH}$ and temperature on growth and sporulation of Alternaria alternata (Fr.) Keissler causing Alternaria blight of chickpea. Legume Research.24 (4): 238-242.

Uppal, B. N., Desai, M. K. and Kamat, M. K. 1938. Alternaria blight of cumin. Indian Journal of Agricultural Science. 7: 49-62.

Varma, P. K., Singh, S. and Gandhi, S. K. 2007. Variability among Alternaria solani isolates causing early blight of tomato. Indian Phytopathology. 60(2): 180- 186.

\section{How to cite this article:}

Sawant, S.B. and Parmar, R.G. 2019. Cultural and Morphological Variability among the Isolates of Alternaria burnsii (Uppal, Patel and Kamat) Causing Blight of Cumin. Int.J.Curr.Microbiol.App.Sci. 8(08): 304-317. doi: https://doi.org/10.20546/ijcmas.2019.808.035 